\title{
Hospital credentialing: time for a (big) change
}

\author{
James Ducharme, MD, CM
}

We now live in an age when information is expected to be universally accessible. It therefore seems anachronistic that a lengthy process is required each time a physician applies for a new provincial licence. Even worse, we suffer through an onerous and seemingly random credentialing process for each hospital where we wish to work. How has such "credentialing isolation" survived so long? When compared to other areas in health care, such as the myriad of applications that allow mobile access to medical information, records, and education or the easily accessible Canadian Medical Association and provincial college websites, the processes of credentialing and licensure are clearly antiquated.

Provincial colleges are taking steps to improve their administrative processes for medical licensure. This process is constrained by the Constitution Act, which mandates that medical licensure is a matter of provincial jurisdiction. Recent legislation has allowed the Federation of Medical Regulatory Authorities of Canada (FMRAC) to standardize the requirements for medical licensure. This "national standard" will enable a physician qualifying for a full licence in one province to be certain of qualifying for full licensure in any other (James Stratford, Registration Department, College of Physicians and Surgeons of Ontario, personal communication, February 14, 2011).

In addition, the FMRAC, along with the Medical Council of Canada, has established a new organization, the Physician Credentials Registry of Canada (PCRC). This national registry will create a physician repository and will perform credentialing on behalf of the provincial licensing authorities. In the future, it should thus be straightforward for a physician who moves between provinces to rapidly obtain any new licence required. The PCRC and the FMRAC are also developing an online national application process using a common form that will be directly routed to the provincial college(s) of interest.

Hospital credentialing, unlike the proposed provincial licensure steps, remains onerous, with each site functioning in isolation. Since moving to Ontario in 2006, I have obtained hospital privileges in over 10 locations. I have yet to identify two with the same credentialing process. Whereas for some, the time required for me to fill out the necessary forms was less than 30 minutes, in one, the credentialing process took almost 15 hours. No hospital is willing to accept another hospital's information unless it is within the same regional health organization. Remarkably, a physician who signs up to do locum emergency department shifts through Health Force Ontario does not have to go through any hospital credentialing process. How can a routine and presumably simple-tostandardize requirement be so varied?

It is self-evident that any health care centre must ensure that its staff are licensed, insured, and free of medical or legal risk. It is not evident, however, why one hospital would require credentialing information that no other hospital requires or why each hospital must have its own distinct process. One solution would be for essential information to be maintained in a centralized database. In fact, much of this will soon be stored in the PCRC. One standardized form would suffice.

It would be even more helpful to separate credentialing requirements from the essential, but typically neglected for physicians, orientation process. As part of credentialing, many hospitals require completion of one or more training modules. These are usually developed locally at considerable expense, despite the

From the Department of Emergency Medicine, McMaster University, Hamilton, ON.

Correspondence to: Dr. James Ducharme, 6711 Mississauga Road, Suite 404, Mississauga, ON L5N 2W3; paindoc22000@yahoo.com.

This article has been peer reviewed.

(c) Canadian Association of Emergency Physicians 
fact that similar materials are readily available elsewhere on the Web. For example, some hospitals in Ontario require completion of their own infection control and hand hygiene education modules for credentialing even though similar resources are available on the College Physicians and Surgeons of Ontario website. Educational material of this nature is more appropriate to an orientation process, which should be undertaken by all staff, including physicians, once privileges are approved. Such orientation could target areas specific to each hospital's functions and be linked to a central site containing modules common to all hospitals.

The time has come for greater collaboration. It would seem reasonable for the Canadian Institute for Health Information to mandate that hospitals agree to a standardized credentialing process. It should be possible to establish and maintain a national physician database, with physicians required to update timesensitive information on a regular basis. This could easily be integrated with the proposed centralized medical licence system.

With a national database, a hospital could download all the required information from the central site.
Rather than a credentialing department for each hospital, there could be one for the whole country. The site would ensure that each physician maintained up-to-date information. Failure to do so would preclude a physician from obtaining or renewing privileges. Provincial colleges could upload any sensitive material, such as ongoing or resolved complaints, and the Canadian Medical Protective Association could upload any pertinent data that hospitals require. All confidential information could be secured and would certainly be more secure than in hospital office filing cabinets.

We are long overdue for our medical administrative processes to align with the age in which we live. There are no longer compelling reasons for each hospital to have its own credentialing process or for each province to independently license physicians. Surely simplifying these processes would make our lives easier and would reduce costs to the health care system by ridding us of many unnecessary administrative layers. Only one question remains: who will lead the way?

Competing interests: None declared.

Keywords: administration, credentialing, hospital systems 